\title{
PREVALENCE OF HYPERTENSION AMONG THE PATIENTS WHO ATTEND MEDICINE OUTDOOR OF DHAKA MEDICAL COLLEGE HOSPITAL
}

\author{
AHMEDUL KABIR ${ }^{1}$, TUSHAR KANTI BARMAN ${ }^{2}$, NUSRAT ARA YOUSUF ${ }^{2}$, NUSRAT FATIMA ${ }^{2}$, \\ JAYANTA BANIK ${ }^{3}$
}

\begin{abstract}
:
Introduction: Worldwide, Hypertension is the established risk factor for many premature cardiovascular morbidity and mortality. Prevalence of hypertension depends on both the racial composition of the population and the criteria used to define the condition and on how extensively the evaluation I done.
\end{abstract}

Objective: To find out the Prevalence of hypertension and also the variation of Prevalence of hypertension, at different age group, rural to urban population, association with other medical conditions and family history of hypertension among the patients who come to seek treatment in Medicine OPD, Dhaka Medical College Hospital.

Materials and Methods: This prospective study was carried out in the medicine outdoor of Dhaka Medical College Hospital during the whole month of July'2007. The patients who attend medicine OPD, DMCH during the month of July'2007 to seek medical treatment were included in the study. Exclusion criteria was who denied to measure Blood pressure or non cooperation of the patient. The diagnosis and classification of hypertension was done according to the JNC-7 report.

A subject was considered hypertensive if one has an average $S B P>140 \mathrm{~mm}$ of $\mathrm{Hg}$ of $D B P>90 \mathrm{~mm}$ of $\mathrm{Hg}$ or if he/ she was already diagnosed as a hypertensive with or without anti-hypertensive medication.

Blood pressure (BP) was measured twice in two arms by using sphygmomanometer. Among the newly detected hypertensive patients, blood pressure was again measured after 15 minutes of rest in handled chair, in calm environment. After second measurement if BP is still more than or equal to $140 / 90 \mathrm{~mm} \mathrm{Hg}$, they were detected as hypertensive. After detecting hypertensive patient, their all data are recorded in a structured questionnaire.

Results: After proper measurement of BP of 17,792 patiens, thypertension was found in 554 patient (3.11\%) of them 181 were male (32.67\%) and 373 were female (67.33\%). So, Prevalence of hypertension among the patient who attend medicine outdoor of DMCH is about $3.11 \%$ and slight this female predominance.

Conclusion: This data may not exactly reflect the actual Prevalence of hypertension as it is outdoor hospital based but give an idea about the Prevalence of hypertension among the patient who attend for treatment in a tertiary based hospital.

\section{Introduction:}

Cardiovascular disease is a major health problem thought the world and a common cause of premature morbidity and mortality. Hypertension is an established major risk factor and the leading cause of cardiovascular disease worldwide, the rate of hypertension and its complications are decreasing in developed countries whereas it is increasing in developing countries. ${ }^{1-4}$ Prevalence of hypertension depends on both the racial composition of the population and the criteria used to define the condition. It also depends on how extensively the evaluation is done. ${ }^{5}$ Prevalence of hypertension very from country to country, population to population and rural to urban. Prevalence of hypertension increases with age and more common in blacks than in whites. ${ }^{6}$ Dubey

1. Resident Physician (RP), Out Patient Department (Medicine), Dhaka Medical College Hospital

2. Medical Officer, Out Patient Department (Medicine), Dhaka Medical College Hospital

3. Post-graduate Trainee, Dept. of Medicine, Dhaka Medical College Hospital 
$\mathrm{VD}^{7}$ carried out one of the earliest study in India (1954), documented 4\% Prevalence of hypertension (criteria;>160/95) amongst industrial workers of kanpur. In 1984 wasir $\mathrm{Hs}$ et $\mathrm{al}^{8}$ reported 3\% Prevalence of hypertension (Criteria :>160/95) in delhi. Another two studies carried out in rural areas of haryana $^{9}$ (1994-95) demonstrated 4.5\% Prevalence of hypertension (JNC V Criteria).In Europe, the Prevalence of hypertension is as high as $44 \%$, while in US, epidemiological data for the period 1999-2002 indicated as prevalence of $28.6 \%$. ${ }^{10,11}$

\section{Materials and Methods:}

The objective of the study to find out Prevalence of hypertension among the patient who attend medicine outdoor of Dhaka medical college hospital. So that we can get an idea about Prevalence of hypertension among the patient who come to seek treatment at a territory based hospital. Other objective is to find out the variation of Prevalence of hypertension at different age group, rural to urban population and also to get a idea about association of other medical conditions among the hypertensive patient and is there any history of hypertension or other medical conditions among the family members of hypertensive patients.

This prospective study was carried out in the medicine outdoor of Dhaka Medical College Hospital during the whole month of July'2007. Inclusion criteria for selection of patient was all the patient who attend medicine outdoor of Dhaka Medical College Hospital during the month of July '2007 to seek medical treatment. Exclusion criteria was who denied to measure Blood pressure or non cooperation of the patient. A subject was considered hypertensive if one has an average Systolic Blood Pressure (SBP) e"140 $\mathrm{mm}$ of $\mathrm{Hg}$ of Diastolic Blood Pressure (DBP) e" 90 $\mathrm{mm}$ of $\mathrm{Hg}$ or if he/ she was already diagnosed as a hypertensive with or without anti-hypertensive medication. The diagnosis and classification of hypertension was done according to the JNC- 7 report. ${ }^{12}$ Blood pressure (BP) was measured twice in two arms by using sphygmomanometer. Among the newly detected hypertensive patients, blood pressure was again measured after 15 minutes of rest in handled chair, in calm environment. After second measurement if $\mathrm{BP}$ is still more than or equal to 140/ $90 \mathrm{mmHg}$, they were detected as hypertensive. After detecting hypertensive patient, their all data are recorded in a structured questionnaire.

\section{Results:}

Study was carried out on 17792 patients; of them 554 were hypertensive (3.11\% of total sample patients) with female predominance of 373 patients $(67.33 \%)$ and male hypertensive patients were 181 (32.67\%) [Table-I(a)].

Among the hypertensive patients 187 (33.75\%) were newly diagnosed case and all ready diagnosed hypertensive patients were 367 (66.25\%) [Table-I(b)].

Regarding type of hypertensive patients Diastolic Blood Pressure was high in $65.77 \%$ patients and Systolic Blood Pressure was raised in $34.22 \%$ of patients. But systolic blood pressure was high in $61.22 \%$ and diastolic blood pressure in $38.78 \%$ among the blood pressure uncontrolled diagnosed hypertensive patients [Table-II].

Table-I (a)

Number of Hypertensive patient.

\begin{tabular}{lcccc}
\hline Sex & No. of sample patient & Percentage(\%) & Hypertensive patient & Percentage(\%) \\
\hline Male & 8766 & $49.27 \%$ & 181 & $32.67 \%$ \\
Female & 9026 & $50.73 \%$ & 373 & $67.33 \%$ \\
\hline Total & 17792 & Total & 554 & $3.11 \%$ of total sample Patient \\
\hline
\end{tabular}

Table-I (b)

Number of Hypertensive patient

\begin{tabular}{llcc}
\hline Type of patient & No. of patient & (\%) \\
\hline $\begin{array}{l}\text { New diagnosed hypertensive } \\
\text { patientn-187 (33.75\%) }\end{array}$ & 187 & $33.75 \%$ \\
$\begin{array}{l}\text { All ready / diagnosed } \\
\text { hypertensive patient }\end{array}$ & $\begin{array}{l}\text { On Anti-hypertensive } \\
\text { treatment / drug } \\
\text { n-367 }\end{array}$ & $\begin{array}{l}\text { Without treatment or } \\
\text { discontinuation of Anti-hypertensive } \\
\text { treatment / drug }\end{array}$ & 689 \\
\hline
\end{tabular}


Table-II

Type of Hypertensive patient.

\begin{tabular}{llll}
\hline Type of patient & & Type of hypertension & Percentage (\%) \\
\hline $\begin{array}{l}\text { New diagnosed hypertensive } \\
\text { patient(n - 187) }\end{array}$ & & Systolic (n - 64) & $34.22 \%$ \\
& & Diastolic (n - 123) & $65.77 \%$ \\
All ready / diagnosed & BP Controlled (n - 106) & - & - \\
hypertensive patient & $28.88 \%$ & & \\
(n-367) & BP Uncontrolled (n - 261) & Systolic (n - 160) & $61.22 \%$ \\
& $71.12 \%$ & Diastolic (n - 101) & $38.78 \%$ \\
\hline
\end{tabular}

Major hypertensive were between the age group of 35 -54 years $(49.64 \%)$ [Table - III].

\section{Table-III}

Age distribution of Hypertensive patient ( $n$ - 554).

\begin{tabular}{lcc}
\hline Age & No. of Patient & Percentage (\%) \\
\hline $13-34$ Years & 101 & $18.23 \%$ \\
$35-54$ Years & 275 & $49.64 \%$ \\
$>55$ Years & 178 & $32.13 \%$ \\
\hline
\end{tabular}

Most of the patients were from urban area (60.10\%) and only $39.90 \%$ patients were from rural area [Table - IV].

Table-IV

Rural \& Urban distribution of Hypertensive patient $(n-554)$.

\begin{tabular}{lcc}
\hline & No. of Patient & Percentage (\%) \\
\hline Rural & 221 & $39.90 \%$ \\
Urban & 333 & $60.10 \%$ \\
\hline
\end{tabular}

Hypertensive patients were have history of some associated medical conditions. Most of 96 patients were have history of Bronchial asthma (55.17\%) and next high associated medical condition was Diabetes Mellitus in 39 patients (22.41\%) [Table-V].

\section{Table-V}

Associated Medical conditions of the Hypertensive patient $n-174(31.40 \%)$

\begin{tabular}{lcc}
\hline Medical Condition & No. of Patient & Percentage (\%) \\
\hline Diabetes Mellitus & 39 & $22.41 \%$ \\
Stroke (CVD) & 11 & $6.32 \%$ \\
Bronchial Asthma & 96 & $55.17 \%$ \\
CRF & 17 & $9.77 \%$ \\
Others & 11 & $6.32 \%$ \\
\hline
\end{tabular}

Lion share of the hypertensive patients having family history of hypertension (55.00\%) and $29.73 \%$ patients were having family history of Stroke (CVD) [TableVI].

\section{Table-VI}

Family history of different Medical conditions among the Hypertensive patient $n-380$ (68.59\%)

\begin{tabular}{lcc}
\hline Medical Condition & No. of Patient & Percentage (\%) \\
\hline Diabetes Mellitus & 17 & $4.47 \%$ \\
Stroke (CVD) & 113 & $29.73 \%$ \\
HTN & 209 & $55.00 \%$ \\
IHD & 41 & $10.79 \%$ \\
\hline
\end{tabular}

\section{Discussion:}

After proper measurement of $\mathrm{BP}$ of 17,792 patients, hypertension was found in 554 patient (3.11\%), of them 181 were male (32.67\%) and 373 were female (67.33\%). So, Prevalence of hypertension among the patient who attend medicine outdoor of DMCH is about $3.11 \%$ and slight female predominance. Although this will not directly reflect the prevalence of hypertension of our community because patient of all socioeconomic status do not attend Medicine Out Patient Department. But it will give an idea about the prevalence of hypertension who seek treatment at a territory hospital. Among the hypertensive patients, 187 patients (33.75\%) were newly diagnosed and 367 patients (66.25\%) were already diagnosed hypertensive patient. Of the already diagnosed hypertensive patients 299 (81.47\%) persons were regularly taking anti-hypertensive drug and only 68 patients(18.53\%) discontinued anti hypertensive drug. Regarding types of hypertension among the newly diagnosed hypertensive patients, 64 patients(34.22\%) had systolic hypertension and 123 patients(65.77\%) 
had diastolic hypertension. So diastolic hypertension is more common among newly diagnosed hypertensive patient. Of the already diagnosed hypertensive patients, only 106 patients (28.88\%) have BP controlled and most of them 261(71.12\%) having uncontrolled BP. Among the persons whose BP is uncontrolled $160(61.22 \%)$ have systolic hypertension and 101(38.78\%) have diastolic hypertension. So systolic hypertension is more in already diagnosed hypertensive patient. In other word it can be said that patient taking anti hypertensive failed to control systolic BP.

Hypertension increase with age and more prevalent after the age of $50 .{ }^{6}$ In our study most of the hypertensive patient are between he group of 35 54years, total number of patients were 275(49.64\%) and then $>55 y e a r s$, where number of patients is 198(32.13\%) but interestingly 101 young patients (18.23\%) were hypertensive in the age group of 13-34 years. 221(39.90\%) patient were from rural area \& major patient $333(60.10 \%)$ were from urban area.

Hypertensive patients are associated with different medical conditions like Diabetes Mellitus (DM), Stroke, Bronchial Asthma, Chronic Renal Failure (CRF), and others like Hypothyroidism, IHD etc. In our study, Bronchial Asthma is most prevalent associated medical condition 96(55.17\%), next associated medical condition are DM 39(22.41\%), Stroke 11(6.32\%), CRF 17(9.77\%) and others $11(6.32 \%)$.

Regarding family history; 209 patients (55.00\%) had history of hypertension in their family members. There is also family history of stroke (CVD), IHD, DM in hypertensive patients, that was found $113(29.73 \%)$, $41(10.79 \%)$ and $17(4.47 \%)$ respectively.

\section{Conclusion:}

Prevalence of hypertension among the patients who attend medicine outdoor of Dhaka medical college hospital is $3.11 \%$ with slight female predominance. Although this data may not exactly reflect the actual Prevalence of hypertension as it is outdoor hospital based, but give a idea about the Prevalence of hypertension among the patient who attend for treatment in a tertiary based hospital. So, for proper evaluation of Prevalence of hypertension need extensive study in both outdoor-indoor of different hospital and in community.

\section{References:}

1. Breithardt G, Eckardt L. The Global Burden of Cardiovascular Diseases. XXIst Annual Congress of the European Society of Cardiology 1999

2. Fuentes $\mathrm{R}$ et al. Hypertension in developing economies: a review of population-based studies carried out from 1980 to 1998. J Hypertens 2000; 18: 521-9.

3. Singh RB et al. Hypertension and stroke in Asia: prevalence, control and strategies in developing countries for prevention. J Hum Hypertens 2000; 14: 749-63.

4. Seedat YK. Hypertension in Developing Nations in Sub-Saharan Africa. J Hum Hypertens 2000; 14: 739-47.

5. Gordon H. Williams. Hypertensive Vascular Disease. In: Harrison's Principles of Internal Medicine, 15th edn. New York: McGraw-Hil, 2001: 1414.

6. Michael Sutters. Systemic Hypertension. Current Medical Diagnosis and Treatment, 46th edn. New York: McGraw - Hil, 2007: 429.

7. Dubey VD. A study on Blood Pressure amongst Industrial workers of Kanpur. J Indiana State Med Assoc 1954; 23: 495-8.

8. Wasir HS, Ramachandran R, Nath LM. Prevalence of hypertension in a closed urban community. Ind Heart J 1984;36: 250-53

9. Malhotra P, Kumari S, Kumar R, Jain S, Sharma BK. Prevalence and determinants of hypertension in an un-industrialised rural population of North India. J Hum Hypertens 1999; 13: 467-72.

10. Hajjari, kitchen Jm, Kotehen TA. Hypertension: trends in prevalence, incidence and control, annu rev. public health 2006;27:465-90

11. Wolf-Maierk, cooper RS, Banegon JR, et al. Hypertension Prevalence and blood pressure levels in 6 European countries, Canada and the united status. JAMA 2003; 289: 2363-9.

12. Chobanian AV et al. National Heart, Lung, and Blood Institute Joint National Committee. The Seventh Report of the Joint National Committee on Prevention, Detection, Evaluation, and Treatment of High Blood Pressure: the JNC 7 report. on Prevention, Detection, Evaluation, and Treatment of High Blood Pressure; National High Blood Pressure Education Program Coordinating Committee. JAMA 2003; 289: 2560-72. 